\title{
Liberation Health and the Role of the Public Health Leader
}

\author{
Courtney Keeler \\ School of Nursing and Health Professions, University of San Francisco, San Francisco, USA \\ Email: ckeeler@usfca.edu
}

Received September $12^{\text {th }}, 2013$; revised October $2^{\text {nd }}, 2013$; accepted October $9^{\text {th }}, 2013$

\begin{abstract}
Copyright (c) 2013 Courtney Keeler. This is an open access article distributed under the Creative Commons Attribution License, which permits unrestricted use, distribution, and reproduction in any medium, provided the original work is properly cited.
\end{abstract}

\begin{abstract}
The following short report lays the groundwork for rethinking the practice and implications of public health leadership in the context of liberation health. Liberation health reduces to a universal idea: health is freedom. In short, everyone holds a subjective notion of health and, within certain bounds, has the right to promote and maintain that health. This report briefly describes liberation health, discusses the implications of liberation health for public health leadership, and outlines two needed transformations in moving towards a liberation health model of leadership. The report details areas for future research on this topic among public health leaders and within public health curricula.
\end{abstract}

Keywords: Healthcare Leadership; Leadership in Public Service; Ethics and Leadership; Leadership in Education and School; Religion and Leadership; Theories of Leadership

\section{Introduction}

As Wiley Souba suggests, the status quo of the United States healthcare system is unsustainable (Souba, 2013), making the role of the public health leader difficult. Albert Einstein defined insanity as "doing the same thing over and over again and expecting different results". In the context of the many ongoing transformations in healthcare driven by a complex array of factors, including the Affordable Care Act, we have an opportunity to break the cycle of insanity; nevertheless, we need a paradigm shift to achieve a more equitable and sustainable system. Building on Souba (2013), we must not only alter how we think about healthcare but also, necessarily, reframe how we think about healthcare leadership, and, within the setting of this report, specifically public health leadership.

The World Health Organization (WHO) believes that public health encompasses “... all organized measures (whether public or private) to prevent disease, promote health, and prolong life among the population as a whole. Its activities aim to provide conditions in which people can be healthy and focus on entire populations, not on individual patients or diseases. Thus, public health is concerned with the total system and not only the eradication of a particular disease” (WHO, 2013). Distinct from the practice of medicine, public health practitioners seek “... to promote population health through shared responsibility, organized efforts, and managed care" (Holmes Jr., 2008: p. xxiv).

The following report lays the groundwork for rethinking the practice and implications of public health leadership in the context of one possible model-liberation health. Liberation health also presents an opportunity for reevaluating public health curricula, and, resultantly, rethinking how we train future public health leaders.

\section{What Is Liberation Health?}

Increasingly, effective public health leadership requires effective health facilitation and advocacy. Many successful public health leaders mirror Greenleaf's (1973) profile of a "servant-leader.” According to Greenleaf (1973), “... the only authority deserving one's allegiance is that which is freely and knowingly granted by the led to the leader in response to, and in proportion to, the clearly evident servant stature of the leader. Those who follow this principle ... will freely respond only to individuals who are chosen as leaders because they are proven and trusted as servants, (Greenleaf, 1973: pp. 3-4).

Augmenting the tenets of servant leadership, liberation health draws from the broader concept of liberation theology, which rallies us to "listen first and foremost to the voices of those who suffer” (Campbell, 1995: pp. 1-2). While the religious context of liberation health may unsettle, the pricklier and more contentious theological indications quickly fade, leaving a secular and universal idea: health is freedom. In short, everyone holds a subjective notion of health and, within certain bounds, has the right to promote and maintain that health.

Campbell describes two types of freedom: "freedom from" or negative freedom and "freedom to" or positive freedom. He explains, "Negative freedom consists of not being prevented from carrying out one's wishes ... Positive freedom, on the other hand, describes an internal as well as an external state, a state in which one is enabled to carry out one's chosen purposes, to control and direct one's own life, and to reevaluate and change that life according to values that transcend individual wants and desires - values gained through interaction with others,” (Campbell, 1995: pp. 12-13). ${ }^{1}$

Therefore, the production of personal freedom in health

${ }^{1}$ To a greater or lesser extent, the boarder community influences individual definitions of health. Akerlof's social interaction theory implies that individual health behaviors and definitions of health result from both a social and individual decision-making process (Akerlof, 1997). As Campbell suggests, each individual has his or her own definition of health and he or she individually chooses health behaviors that promote or hinder that health nevertheless, social networks (e.g., family, peer groups, community) shape what behaviors are socially acceptable. Resultantly, social interaction impacts individual perceptions of health and health freedom as well as one's ability to achieve freedom in health choices. 
choices results from a system of checks and balances. In economic terms, communities seek to limit negative externalities (e.g., secondhand smoke) and encourage positive externalities (e.g., vaccinations).

So, how do public health leaders fit into this picture? Campbell proposes that "The freedom we are looking for is not something others can grant, but it may be made possible by the way we make ourselves available to one another..." (Campbell, 1995: p. 15). Most public health officials will tell you that their constituents can identify the health problems plaguing their communities; however, too many communities simply do not have the resources to enact change. Therefore, "it is essential to listen...," (Campbell, 1995: p. 18) to one’s community. Moving away from a paternalistic model, the good public health leader listens and helps community members facilitate the change needed to enable health equity, where community members have the freedom to pursue and maintain health. Therefore, “... proven and trusted as servants” (Greenleaf, 1973: p. 4), liberation health indicates that public health leaders can affect socially just change through facilitation, attention, and awareness.

\section{Enabling Transformation}

Taken together, servant leadership and liberation health challenge our perceived notion of public health leadership, emphasizing that, at some level, public health leadership is in fact public health facilitation. Liberation health spurs us to ask: how can those working in positions of public health leadership promote and maintain individual and community ideals of health?

While our health care system continues to undergo quite a few changes, transformation is necessary. Unlike change, which improves something that is already possible, "transformation is a function of altering the way you are being - to create something that is currently not possible in your reality" (Souba, 2013: p. 45).

At a macro-level, system-wide factors impede the broad implementation of liberation health principles. Souba (2013) emphasizes the instability of our healthcare system. Importantly, many Americans simply cannot attain (or afford to attain) desired health behaviors. For instance, even following Massachusetts's landmark health legislation, many in the state still cannot afford healthcare (Clark et al., 2011). ${ }^{2}$ While health equality may be impossible, the optimal healthcare system should ideally be equitable. Liberation health stresses that every individual should have the ability to pursue health behaviors of her choosing, which would be possible in an equitable regime.

Prior to any system-wide transformations, public health leadership must also evolve. As suggested by this report, liberation health offers one of many possible templates.

In moving towards a liberation health model of leadership, two transformations must take place. First, public health leaders must embrace socially just, client-centered systems of practice, where communities freely participate and serve as active stakeholders in the process. Second, baccalaureate and post-baccalaureate curricula must reflect this practice.

First and foremost, however, we need to evaluate whether our goals and missions align (both practically and ethically)

\footnotetext{
${ }^{2}$ Clark and colleagues (2011) write, "We found that nearly a quarter of adults who were in fair or poor health reported being unable to see a doctor because of cost during the implementation of the reforms."
}

with the tenets of liberation health. In this process, we must reflect on our vision at an aggregate and individual level. As McKee and colleagues write, "Having a personally inspiring vision helps [one] see how [one] can make a positive contribution to the world. What makes the world a better place for [oneself] being with us? The answer to this question is probably linked to [one's] sense of calling, mission, and purpose in life," (McKee et al., 2008: p. 73). Is liberation health the right approach; and, if so, how can we promote this transformation?

\section{An Example of Liberation Health in Public Health Practice}

Mobilizing for Action through Planning and Partnerships (MAPP) offers a practical example of liberation health. An important caveat, MAPP does not directly incorporate liberation health by name into its framework nor does the National Association of County and City Health Officials (NACCHO), a champion of MAPP, reference liberation health. Rather, I identify a common theme in the MAPP process and liberation health, namely the acknowledgement of a community driven characterization of health and the struggle to realize that health through community involvement and partnerships.

NACCHO describes MAPP as “... a community-driven strategic planning process for improving community health. Facilitated by public health leaders, this framework helps communities apply strategic thinking to prioritize public health issues and identify resources to address them," (NACCHO, 2013a, emphasis added). Notably, MAPP reflects a community directed process, where community members have the opportunity to define health in their own terms as well as identify and tackle obstacles inhibiting this health. Inherent to the MAPP process, being an effective public health leader means being an effective health facilitator, advocate, and servant-leader.

NACCHO provides a wonderful outline of the six, iterative stages of the MAPP process on their website; each of these stages resonates with the liberation health philosophy. For instance, the initial, "organizational phase” of MAPP involves the creation of likely and unlikely community partnerships; these champions shepherd transformations within the community (NACCHO, 2013b). During the subsequent "visioning phase," leaders "[guide] the community through a collaborative, creative process that leads to a shared community vision and common values" (NACCHO, 2013c).

Public health departments across the country are increasingly turning to MAPP as a strategic planning tool, perhaps signaling that the public health community is ready for a transformation broadly along the lines of the liberation health philosophy.

\section{Conclusion and Future Research}

Health is freedom; liberation health simply formalizes this premise. Everyone holds a subjective notion of health and, within certain bounds, has the right to promote and maintain that health. Based on this philosophy, effective public health leadership requires facilitation, attention, and awareness.

Discussing the convergence of morality, politics, and health policy, Morone highlights “... that classical political wisdom: build a constituency” (Morone, 2005: p. 21). Liberation health emphasizes that this relationship runs both ways. While public health leaders lead their constituents, they also have a fundamental responsibility to listen and facilitate. Paraphrasing 
Greenleaf (1973), public health leaders must be true and trusted servants.

In moving towards a liberation health model of leadership, I discuss two necessary transformations, the first among public health leaders and the second within public health curricula. Both arenas present opportunities for future research.

For instance, in terms of public health leadership and public health practice, one might consider whether organizations, and equally importantly, organizational leaders, who embrace liberation health philosophy experience improved patient/client outcomes and higher levels of productivity.

Reflecting on the next generation of public health leaders, public health education presents another prospect for novel and important research. To what extent do colleges and universities incorporate the idea of "health as freedom" into their public health curricula? Do students who graduate from programs with a liberation health focus become relatively more successful public health leaders? Do these students hold an elevated commitment to social justice? Does incorporating topics like MAPP into the classroom curriculum enhance student credibility from the perspective of potential employers and community partners? Liberation health closely aligns with cultural competency; does discussing issues like cultural competency and stereotype threats (Steele, 2010) in the context of liberation health augment student learning? As MAPP and other liberation health analogues emerge in public health curricula, researchers can attempt to answer these questions. Indeed, some opportunities for this research at the university level likely already exist.

\section{Acknowledgements}

Thanks to Judith Karshmer and Kia James at the University of San Francisco.

\section{REFERENCES}

Akerlof, G. A. (1997). Social distance and social decisions. Econometrica, 65, 1005-1027. http://dx.doi.org/10.2307/2171877

Campbell, A. V. (1995). Health as liberation: Medicine, theology, and the quest for justice. Cleveland, OH: Pilgrim Press.

Clark, C. R., Soukup, J., Govindarajulu, U., Riden, H. E., Tovar, D. A., \& Johnson, P. A. (2011). Lack of access due to costs remains a problem for some in Massachusetts despite the state's health reforms. Health Affairs, 30, 247-255. http://dx.doi.org/10.1377/hlthaff.2010.0319

Greenleaf, R. K. (1973). The servant as leader. Ann Arbor, MI: University of Michigan.

Holmes, L. (2008). Basics of public health core competencies. Sudbury, MA: Jones \& Bartlett Publishers.

McKee, A., Boyatzis, R. E., \& Johnston, F. (2008). Becoming a resonant leader: Develop your emotional intelligence: Renew your relationship: Sustain your effectiveness. Boston, MA: Harvard Business School Press.

Morone, J. A. (2005). Morality, politics, and health policy. In Policy Challenges in Modern Health Care (pp. 13-25). New Brunswick, NJ: Rutgers University Press.

National Association of County \& City Health Officials (2013a). MAPP Framework.

http://www.naccho.org/topics/infrastructure/mapp/framework/

National Association of County \& City Health Officials (2013b). MAPP_Framework: 1. Organizing. http://www.naccho.org/topics/infrastructure/mapp/framework/phase1 . $\mathrm{cfm}$

National Association of County \& City Health Officials (2013c). MAPP_Framework: 2. Visioning. http://www.naccho.org/topics/infrastructure/mapp/framework/phase2 .cfm

Souba, W. W. (2013). The science of leading yourself: A missing piece in the health care transformation puzzle. Open Journal of Leadership, 2, 45-55. http://dx.doi.org/10.4236/ojl.2013.23006

Steele, C. (2010). Whistling Vivaldi: And other clues to how stereotypes affect us (issues of our time). New York: WW Norton \& Company.

World Health Organization (2013). Trade, foreign policy, diplomacy and health: Glossary of globalization, trade, and health terms. http://www.who.int/trade/glossary/story076/en/ 